\title{
Modification of Low-Density Slag Cementing Slurry with SiC Whiskers at High Temperature
}

\author{
Hongqiong Fu, ${ }^{1,2}$ Xiaoyang Guo $\mathbb{D}^{1},{ }^{1}$ PingZhou, ${ }^{3}$ Ping Yan, ${ }^{4}$ Youzhi Zheng, ${ }^{2}$ Lu Liu, ${ }^{3}$ Jie Wu, ${ }^{3}$ \\ and Ming $\mathrm{Li} \mathbb{D}^{1,3}$ \\ ${ }^{1}$ State Key Laboratory of Oil and Gas Reservoir Geology and Exploration, South Petroleum University, Chengdu, \\ Sichuan 610050, China \\ ${ }^{2}$ Engineering Technology Research Institute, PetroChina Southwest Oil \& Gas Field Company, Guanghan, Sichuan 618300, China \\ ${ }^{3}$ School of New Energy and Materials, Southwest Petroleum University, Chengdu, Sichuan 610500, China \\ ${ }^{4}$ College of Chemistry and Environmental Protection Engineering, Southwest Minzu University, Chengdu, Sichuan 610041, China
}

Correspondence should be addressed to Xiaoyang Guo; yj1951028@qq.com and Ming Li; swpulm@126.com

Received 8 July 2021; Revised 27 September 2021; Accepted 28 September 2021; Published 11 October 2021

Academic Editor: Antonio Caggiano

Copyright ( 92021 Hongqiong Fu et al. This is an open access article distributed under the Creative Commons Attribution License, which permits unrestricted use, distribution, and reproduction in any medium, provided the original work is properly cited.

\begin{abstract}
The aim of this study was to improve the mechanical properties of a slag solidified body at high temperatures. Composite materials with different contents of $\mathrm{SiC}$ whiskers were prepared and characterized using techniques such as mechanical testing, scanning electron microscopy (SEM), X-ray diffraction (XRD), thermogravimetric analysis (TGA), and Fourier transform infrared spectroscopy (FT-IR). When the $\mathrm{SiC}$ whisker addition is $1 \%$ mass percentage, the compressive and tensile strength of the slag solidified body after hydration for 7 days increased by $10.2 \%$ and $39.3 \%$, respectively, and Young's modulus decreased by $16.8 \%$. The results show that the addition of $\mathrm{SiC}$ whiskers can enhance the mechanical properties of solidified slag bodies at high temperatures. According to the test results, the hydration products of the slag solidified body mainly consist of honeycomb tobermorite $(\mathrm{C}-\mathrm{S}-\mathrm{H})$ gel at high temperatures in addition to a small number of spherical products. The spheres are connected to form a dense structure; however, noticeable cracks were present. The addition of $\mathrm{SiC}$ whiskers effectively inhibited the initiation and further development of microcracks and improved the bearing capacity of the slag solidified body.
\end{abstract}

\section{Introduction}

Well cementing is an important part of drilling and completion engineering [1]. Improving the displacement efficiency is one of the methods to enhance the quality of cementing in complex oil and gas wells [2]. Silicate cement is currently the most widely used cementitious material [3]. However, the chemical incompatibility of the cement slurry with the drilling fluid is a key factor contributing to the low replacement efficiency. In the investigation of cementitious materials with similar hydraulic properties to cement, blast furnace slag, with its high activity, high early strength, and low cost, has received considerable attention [4]. Slag concrete has low compressive strength in the early stages and high long-term compressive strength $[5,6]$. Slag mud-tocement (MTC) technology was originally developed with slag as the cementing material. This refers to the process where the blast furnace water quench slag is replaced by traditional weighted materials and is mixed into the drilling fluid, such that the drilling fluid itself or the drilling fluid filter cake contains potentially active slag [7]. Specific activators are added during the drilling and completion process to ensure that the drilling fluid contains slag and that the drilling fluid filter cake has curing abilities when cementing [8]. With the extensive application of slag MTC technology, it was found that the slag solidified body exhibits strength deterioration and even cracking at high temperatures. This problem has limited its application and development. You compared ordinary polonite cement with alkali-activated slag and found that alkali-activated slag takes less time to set. Additionally, the chloride ion diffusion coefficient and water absorption rate of alkali-activated slag 
are much lower than those of ordinary polonite cement at the same strength [5]. Qiu et al. [9] studied the reason for the strength decline and the cracking mechanism of the slag solidified body under high temperatures and concluded that the addition of slag can effectively enhance the self-healing properties of the slag body. Hosan and Ahmed Shaikh increased the compressive strength of the slag by adding nano $\mathrm{CaCO}_{3}[10]$. Li et al. studied the improvement of slag performance using brucite fibers and found that the addition of $6 \%$ brucite fiber greatly improved the mechanical properties of solidified slag [11]. Wu et al. reported an improvement in the cementation strength and hydration product yield in the early stages of slag activation [12]. Manjunath et al. improved the compressive and shear strength of slag by alkali activation [13].

The content of the materials added to the solidified slag body can affect its rheological properties, compressive strength, flexural strength, voids, and permeability [14]. However, only a few methods have been reported to improve the mechanical properties of slag, specifically, to improve its high brittleness and strength decline $[15,16]$. Several researchers have chosen nanoparticles or fibrous whisker materials as additives for toughening [17-20]. Therefore, in this study, $\mathrm{SiC}$ whiskers were added to the base slurry to improve the physical properties of the solidified slag body. Therefore, in order to improve the mechanical properties of slag at high temperature, $\mathrm{SiC}$ whisker was introduced into the slag system. The authors quantified the effect of whisker on mechanical properties of slag system by compressive, tensile, and triaxial mechanical tests. In addition, scanning electron microscopy (SEM), X-ray diffraction (XRD), Fourier transform infrared spectroscopy (FT-IR), and thermogravimetric analysis (TGA) were used to elucidate the strengthening mechanism of the $\mathrm{SiC}$ whiskers.

\section{Experimental Setup}

2.1. Materials. The slag was supplied by the ying'an environmental protection material technology company (Shandong, China). Scanning electron microscope was used to test the apparent morphology of the $\mathrm{SiC}$ whisker, and the test results are shown in Figure 1. The particle size of $\mathrm{SiC}$ whisker was tested by laser particle size tester, and the results are shown in Figure 2. The main properties of the $\mathrm{SiC}$ whiskers were tested according to the standard of GB176-62. X-ray fluorescence spectrometry (XRF) was used for elemental analysis of slag, and the test results are shown in Tables 1, and 2 shows some basic characteristics of slag, which can be tested by a particle size analyzer. Since Tables 2 and 3 are only to show the basic parameters of slag and whiskers, error analysis is not necessary. Therefore, the tests were not repeated. Other materials such as the activator JHQ (alkali metal hydroxide), retardant (HX-31L), suspension agent (sodium carboxymethyl cellulose), and dispersant (sulfonated tannins) were obtained in China from commercial suppliers.

2.2. Specimen Preparation and Experimental Methods. According to the Chinese Standard GB/T203-78, the activity coefficient of blast furnace slag should not be less than 1.121,

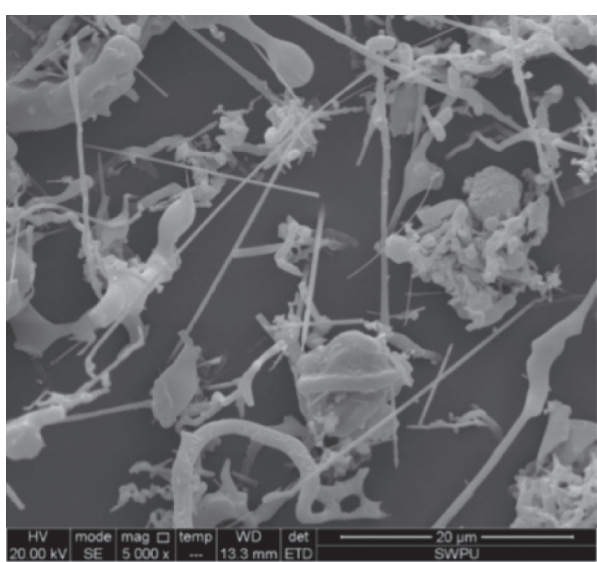

Figure 1: Microstructure of SiC whiskers.

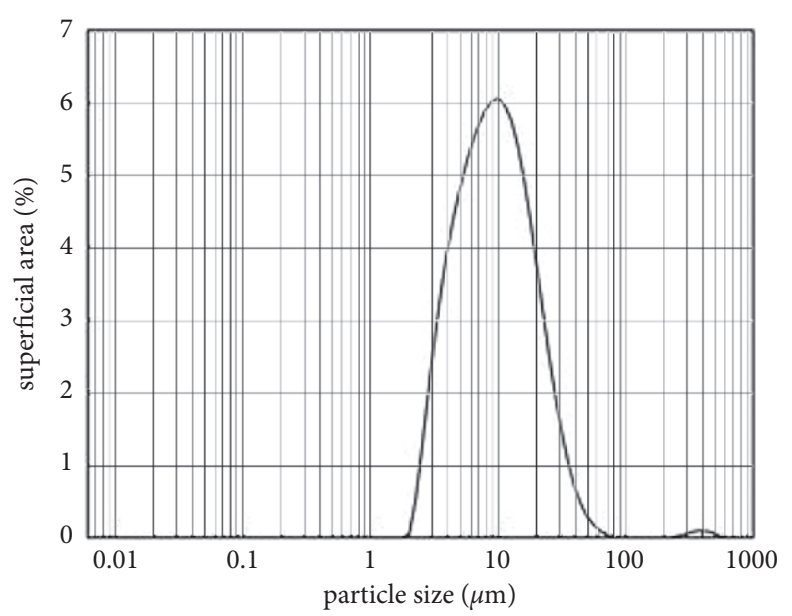

Figure 2: Particle size distribution of SiC whiskers.

TAble 1: The chemical composition of slag.

\begin{tabular}{lcccccccc}
\hline $\mathrm{ID}$ & $\mathrm{SiO}_{2}$ & $\mathrm{Al}_{2} \mathrm{O}_{3}$ & $\mathrm{Fe}_{2} \mathrm{O}_{3}$ & $\mathrm{CaO}$ & $\mathrm{MgO}$ & $\mathrm{TiO}_{2}$ & $\mathrm{MnO}$ & Other \\
\hline $\mathrm{SS} 95$ & 32.27 & 13.88 & 0.37 & 36.90 & 9.26 & 0.96 & 0.39 & 5.97 \\
\hline
\end{tabular}

The units of chemical components in the table are wt.\%.

whereas the activity coefficient of the cementing slag should be greater than 1.50. JHQ is an activator and used to initiate the potential hydration activity of the slag to achieve the solidification effect of the cementing fluid. The fluidity and suspension stability of the slurry were adjusted using a sodium carboxymethyl cellulose as a suspension agent. Sodium carboxymethyl cellulose was dissolved in water and stirred for $30 \mathrm{~min}$. Different proportions of $\mathrm{SiC}$ whiskers were evenly mixed with the slag. A cement slurry constant speed mixer (TG-3060) from the Institute of Applied Technology of the Shenyang Institute of Aeronautical Engineering was used to stir the slurry. Table 4 lists the slurry formulations. The mass of the silicon carbide whisker was substituted for the same mass of the slag. Then, the prepared base slurry was poured into a standard curing mold and cured at a relative humidity of $100 \%$ and $90^{\circ} \mathrm{C}$ for 3 and 7 
TABLe 2: Properties of slag particles.

\begin{tabular}{|c|c|c|c|c|}
\hline ID & Density $\left(\mathrm{g} \cdot \mathrm{cm}^{3}\right)$ & Special surface area $\left(\mathrm{m}^{2} \cdot \mathrm{g}^{-1}\right)$ & $\begin{array}{c}\text { average } \\
\text { particle size } \\
(\mu \mathrm{m})\end{array}$ & Volumetric mean particle size $(\mu \mathrm{m})$ \\
\hline SS95 & 2.90 & 1.121 & 1.846 & 4.651 \\
\hline
\end{tabular}

TABle 3: Properties of silicon carbide whisker.

\begin{tabular}{lcccccc}
\hline Sample name & Colour & Density $\left(\mathrm{g} . \mathrm{cm}^{-3}\right)$ & Length $(\mu \mathrm{m})$ & Diameter $(\mu \mathrm{m})$ & Tensile strength $(\mathrm{GPa})$ & Elastic modulus $(\mathrm{GPa})$ \\
\hline SiC whisker & Celadon & 3.21 & $50-250$ & $0.5-2.5$ & 20.5 & 480.2 \\
\hline
\end{tabular}

TABLE 4: Formulations of the base slurry.

\begin{tabular}{lcccccc}
\hline Sample & Slag $(\mathrm{g})$ & SiC whisker $(\mathrm{g})$ & Activator $(\mathrm{g})$ & Suspension agent $(\mathrm{g})$ & Dispersant $(\mathrm{g})$ & Water $(\mathrm{g})$ \\
\hline V & 100 & 0 & 5 & 0.4 & 0.5 & 75 \\
S1 & 99.5 & 0.5 & 5 & 0.4 & 0.5 & 75 \\
S2 & 99 & 1 & 5 & 0.4 & 0.5 & 75 \\
S3 & 98.5 & 1.5 & 5 & 0.4 & 0.5 & 75 \\
S4 & 98 & 2 & 5 & 0.4 & 0.5 & 75 \\
\hline
\end{tabular}

days. Table 5 shows the activity coefficient $(\mathrm{M})$ and the quality coefficient $(\mathrm{K})$ of the slag system which were calculated as follows:

$$
\begin{gathered}
\mathrm{M}=\frac{\left(\mathrm{CaO}+\mathrm{MgO}+\mathrm{Al}_{2} \mathrm{O}_{3}\right)}{\left(\mathrm{SiO}_{2}+\mathrm{Fe}_{2} \mathrm{O}_{3}\right)}, \\
\mathrm{K}=\frac{\left(\mathrm{CaO}+\mathrm{MgO}+\mathrm{Al}_{2} \mathrm{O}_{3}\right)}{\left(\mathrm{SiO}_{2}+\mathrm{TiO}_{2}+\mathrm{MnO}\right)} .
\end{gathered}
$$

\section{Results and Discussion}

\subsection{Mechanical Properties}

3.1.1. Compressive Strength and Tensile Strength. Figure 3 shows the average compressive strength and splitting tensile strength of the virgin base slurry (V) and the slag with different $\mathrm{SiC}$ whisker contents (S1, S2, S3, and S4). Three repeated measurements were made for each set of data, from which error bars were plotted. The error bar takes the measured arithmetic mean as the midpoint, reflecting the dispersion degree of each set of data, and half of the length of the line segment is equal to the uncertainty. As can be seen from Figure 3(a), the compressive strength of samples V-S4 increases with the curing time increasing from 3 to 7 days, indicating that the compressive strength of slag system increases with the extension of slag hydration time. After curing for 3 days and 7 days, the compressive strength of S1-S4 samples is higher than that of V sample. Among them, it is more obvious under 7-day curing condition. The compressive strength of $\mathrm{V}$ sample is $21.12 \mathrm{MPa}$. On this basis, the compressive strength of $\mathrm{S} 1$ sample is increased by $5.9 \%$, that of S2 is increased by $10.2 \%$, that of S3 is increased by $9.8 \%$, and that of S4 is increased by $10.8 \%$.
TABLE 5: The activity coefficient (M) and quality coefficient $(\mathrm{K})$ of slag.

\begin{tabular}{lcc}
\hline ID & Activity coefficient $(\mathrm{M})$ & Quality coefficient (K) \\
\hline SS95 & 1.84 & 1.79 \\
\hline
\end{tabular}

As can be seen from Figure 3(b), the splitting tensile strength of samples increases with the extension of curing time. The splitting tensile strength of S1-S4 was higher than that of $\mathrm{V}$ at different test times, and the splitting tensile strength increased more at 7 days. The splitting tensile strength of V is 2.06. On this basis, $\mathrm{S} 1$ is improved by $22.3 \%$, $\mathrm{S} 2$ is improved by $39.3 \%, \mathrm{~S} 3$ is improved by $31.5 \%$, and S4 is improved by $28.2 \%$.

With the extension of curing time, the slag will undergo hydration reaction. The hydration products of alkali slag materials are mainly calcium silicate hydrate gel, aluminum calcium silicate hydrate, and other crystals, with less crystal content, making the curing body more prone to dry shrinkage and cracking phenomenon. After the SiC whisker is added, these results demonstrate that $\mathrm{SiC}$ whiskers can effectively improve the compressive and tensile strength of the slag, improving the overall mechanical properties of the slag solidified body. When the addition of $\mathrm{SiC}$ whiskers was $1 \%$, the toughening effect on the slag solidified body was the greatest. This may be because the whisker controls the generation and development of microcracks through bridging, pulling out, filling, and other effects, so that the slag system can maintain high and lasting mechanical integrity. The mechanism of action needs to be further verified by the microscopic morphology test.

3.1.2. Triaxial Stress-Strain Curves. It can be seen from the previous compression and tensile tests that when the 


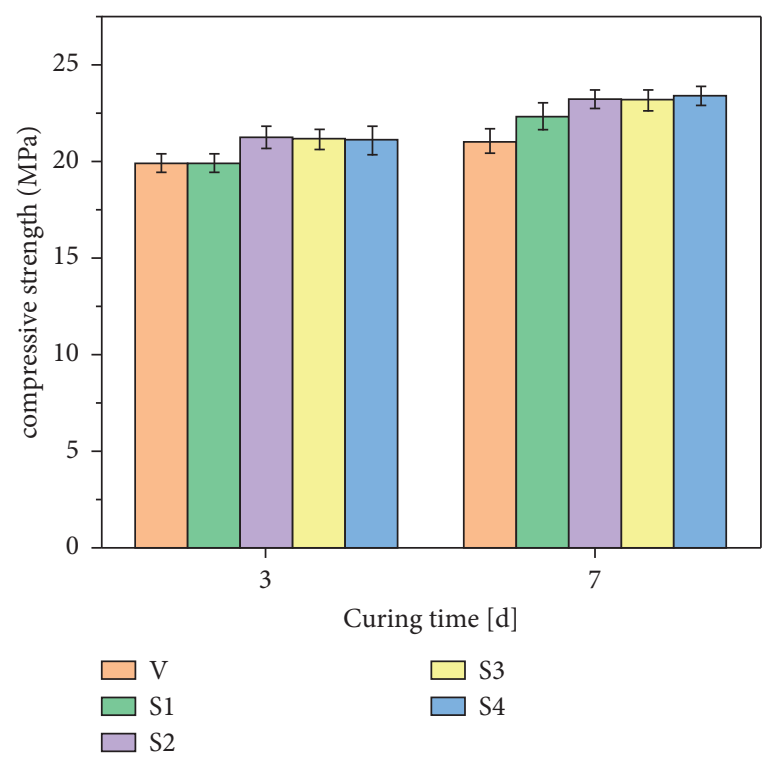

(a)

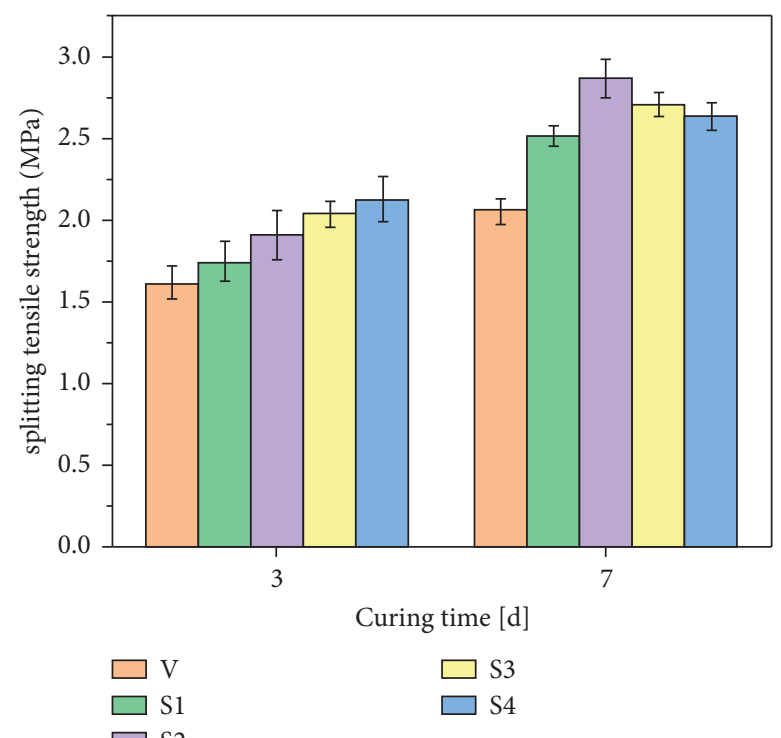

(b)

FIGURE 3: Influences of different curing times and different amounts of $\mathrm{SiC}$ whisker on the mechanical properties of slag. (a) Compressive strength. (b) Splitting tensile strength.

addition of $\mathrm{SiC}$ whiskers was $1 \%$, the toughening effect on the slag solidified body was the greatest. In order to further illustrate the effect of $\mathrm{SiC}$ whisker on the properties of solidified solids, triaxial tests were carried out on solidified solids (S2) and blank specimens (V) added with $1 \% \mathrm{SiC}$ whisker slag. The test results are shown in Figure 4. The test was performed at $90^{\circ} \mathrm{C}$ and $10 \mathrm{MPa}$ confining pressure, with constant speed loading at $1.6 \mathrm{kN} / \mathrm{min}$ until the sample broke.

The peak value of the curve represents the compressive strength value of the solidified body. When the stress drops rapidly after reaching the peak value, it indicates that the brittleness is large. If the stress drops gently, it indicates that the material has good toughness. It can be seen from the experimental results that under constant large strain, the curve peak of sample $\mathrm{S} 2$ is higher than that of sample $\mathrm{P}$, and the bearing capacity of the solidified body containing SiC whisker (S2) is much higher than that of the blank sample $(\mathrm{V})$. Before reaching the curve platform, the slope of the stress-strain curve represents the elastic modulus of the sample. As can be seen from the figure, the slope of S2 sample is significantly larger than that of $\mathrm{V}$ sample, so the elastic modulus of S2 sample is larger than that of V sample, indicating that S2 sample has better toughness. The calculation results of its elastic modulus are shown in Table 6. In the triaxial stress state, the difference of two principal stresses is the axial differential stress. The axial differential stress can represent expansion and deformation, and the larger the value is, the larger the deformation is and the better the toughness is. It can be seen from Table 6 that the axial differential stress of S2 sample is greater than that of $\mathrm{V}$ sample, which further indicates that $\mathrm{SiC}$ whisker can improve the toughness of slag system.

\subsection{Phase and Micromorphological Analysis of the Solidified Body}

3.2.1. Microstructure. Figure 5 shows the distribution of S2, that is, the addition of SiC whiskers accounts for $1 \mathrm{wt} . \%$ of the system (slag $+\mathrm{SiC}$ whiskers). The hydration products touch and overlap each other to form a spatial grid structure. However, if the hydration products are not tightly combined, there will still be microcracks. The whisker carried some of the external load and bridged the two sides of the microcrack, which dispersed some amount of energy and prevented the continuous growth of the crack. However, there is an interface between the whisker and the slag. When the shear force acting on the whisker is greater than the binding force between the whisker and the slag-based material interface, the whisker is unstuck or even pulled out, which requires a significant amount of energy. The energy of the microcracks dissipates when a large number of whiskers are pulled out. This reduces the degree of crack tip stress concentration while simultaneously slowing down the crack initiation and development, thus improving the toughness of the slag solidified body.

3.2.2. X-Ray Diffraction Analysis. In order to investigate whether the addition of $\mathrm{SiC}$ whisker would cause changes in hydration products of slag, XRD tests were carried out on the powder of solidified slag (S2) and blank sample (V) containing $\mathrm{SiC}$ whisker after 7 -day hydration at $90^{\circ} \mathrm{C}$. The results are shown in Figure 6. By analyzing and comparing the patterns of samples without and with $\mathrm{SiC}$ whisker, it can be seen that the positions and intensity of diffraction peaks of the two peaks are almost the same. It can be seen that no new phase is generated in the slag hydration products with 


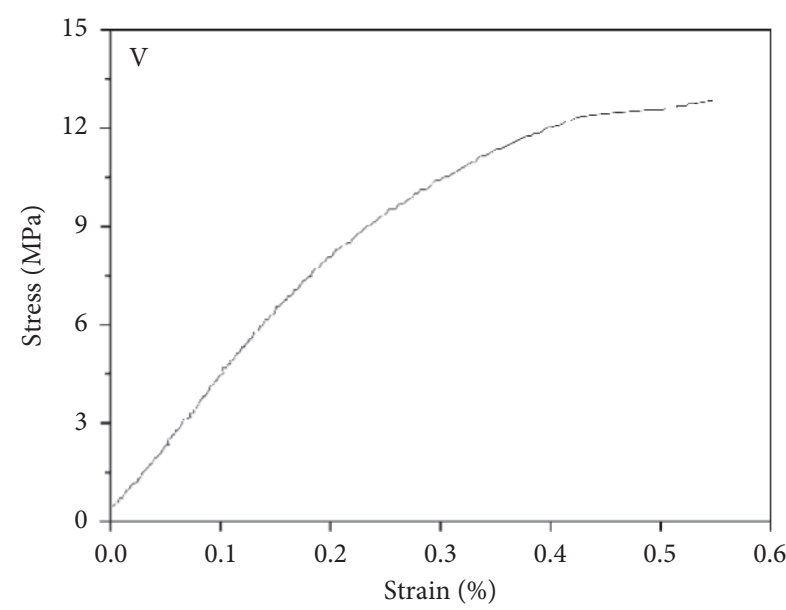

(a)

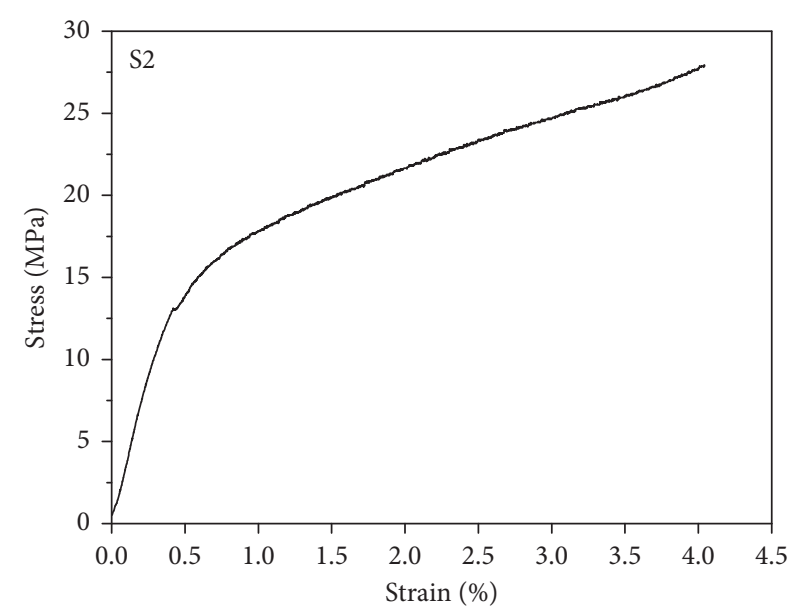

(b)

Figure 4: Triaxial stress-strain curve. (a) Without adding SiC whisker. (b) $1 \% \mathrm{SiC}$ whisker added.

TABLE 6: Basic parameters of mechanical properties of $\mathrm{SiC}$ whisker solidified (S2) and without SiC whisker (V).

\begin{tabular}{lccc}
\hline Sample & Elasticity modulus $(\mathrm{MPa})$ & Maximum deformability $(\%)$ & Axial differential stress $(\mathrm{MPa})$ \\
\hline $\mathrm{V}$ & 4350.5 & 0.55 & 12.9 \\
S2 & 3620.0 & 4.04 & 27.8 \\
\hline
\end{tabular}

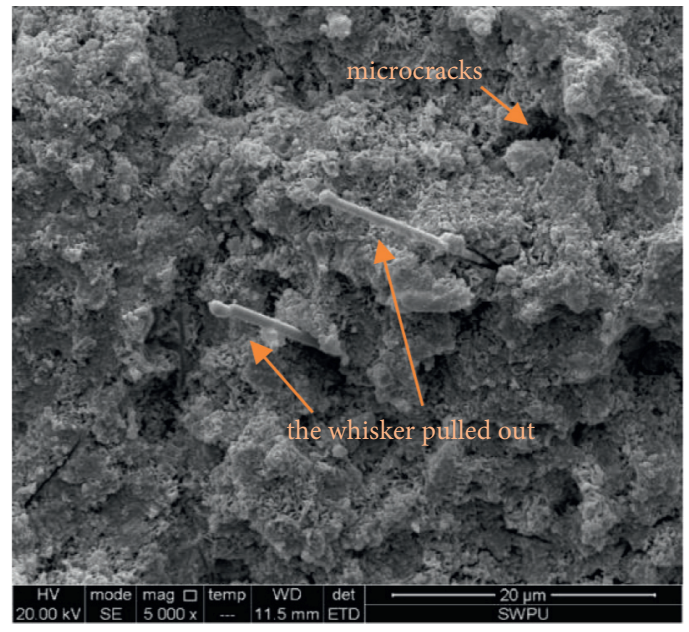

(a)

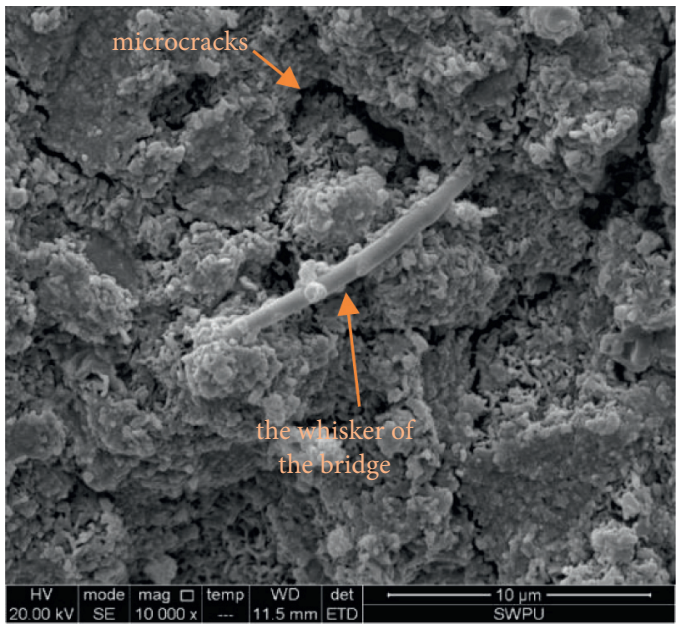

(b)

FIGURE 5: SEM micrograph of S2: (a) low magnification; (b) high magnification.

whisker, and the composition and content of the slag hydration products are not affected. After 7 days of alkalistimulated hydration, the products are calcium silicate hydrate $(\mathrm{C}-\mathrm{S}-\mathrm{H})$ gel, calcium silica $\left(\mathrm{C}_{3} \mathrm{~S}_{2}\right)$, zeolite minerals, and a small amount of $\mathrm{CaCO}_{3}$ [21]. Among them, $\mathrm{CaCO}_{3}$ should be carbonized from $\mathrm{CO}_{2}$ absorbed by slag in the hydration process. In conclusion, the addition of $\mathrm{SiC}$ whisker has almost no effect on the composition and content of slag hydration products and does not affect the hydration reaction process of slag cementing fluid in engineering application.
3.2.3. Fourier Transform Infrared Spectroscopy Analysis. Figure 7 shows the infrared (IR) spectra of slag solidified bodies with and without $\mathrm{SiC}$ whiskers hydrated for $7 \mathrm{~d}$ at $90^{\circ} \mathrm{C}$. The absorption peak at $3459 \mathrm{~cm}^{-1}$ represents the stretching vibration of $[\mathrm{OH}]^{-}$. The absorption peak at $1639 \mathrm{~cm}^{-1}$ characterizes the bending vibration of the hydroxyl group of the $-\mathrm{O}-\mathrm{H}$ bond. The absorption peaks at $1427 \mathrm{~cm}^{-1}$ and $891 \mathrm{~cm}^{-1}$ represent the asymmetric stretching vibration of $\mathrm{CO}_{3}{ }^{2-}$. This may have been caused by the absorption of $\mathrm{CO}_{2}$ in the air during the preparation of the slag samples. The absorption band at the wavenumber, $962 \mathrm{~cm}^{-1}$, 

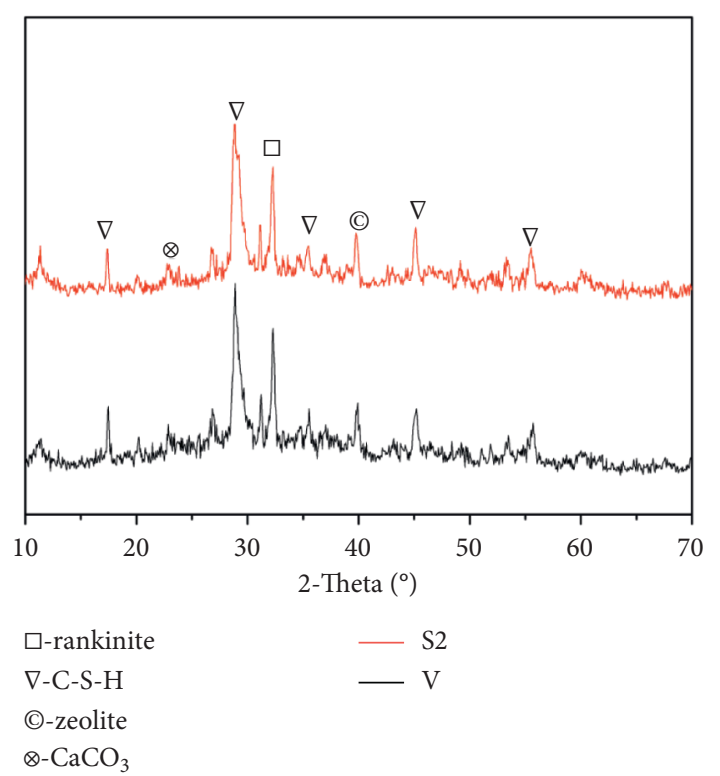

FIGURE 6: XRD patterns of slag solidified body without adding SiC whisker (V) and with $1 \% \mathrm{SiC}$ whisker (S2).

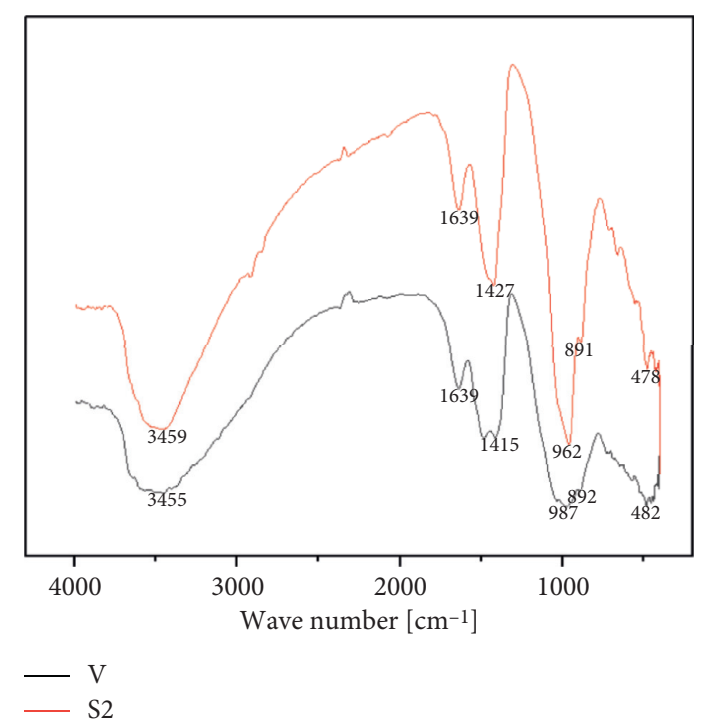

FIGURE 7: IR spectra of slag solidified body without adding $\mathrm{SiC}$ whisker (V) and with $1 \% \mathrm{SiC}$ whisker (S2).

is the infrared spectrum of the asymmetric stretching vibration of the $\mathrm{Si}-\mathrm{O}$ bond of the tobermorite gel in the $\left[\mathrm{SiO}_{4}\right]$

${ }^{4-}$ tetrahedron [22]. When polymerized as Si-O-Si bonds, the asymmetric stretching vibration has a large absorption band at $962 \mathrm{~cm}^{-1}$, indicating a large number of $\left[\mathrm{SiO}_{3}\right]^{2-}$ and $\left[\mathrm{SiO}_{4}\right]^{4-}$ structures, that is, a large number of tobermorite products were generated [23]. The absorption band at $478 \mathrm{~cm}^{-1}$ indicates the presence of a certain number of $\left[\mathrm{AlO}_{4}\right]^{5-}$ and $\left[\mathrm{AlO}_{6}\right]^{9-}$ structures. In conclusion, there are several $\mathrm{Si}-\mathrm{O}$ bonds, $\mathrm{Al}-\mathrm{O}$ bonds, $\mathrm{Si}-\mathrm{O}-\mathrm{Si}$ bonds, and $\mathrm{Al}-\mathrm{O}-\mathrm{Si}$ bonds in the slag. These bonds form a three-dimensional network structure composed of $\mathrm{Si}, \mathrm{Al}$, and $\mathrm{O}$. The presence of the $\left[\mathrm{SiO}_{4}\right]^{4-}$ and $\left[\mathrm{AlO}_{4}\right]^{5-}$ bond absorption bands indicates that the inorganic substance was composed of $\left[\mathrm{SiO}_{4}\right]$ tetrahedra and $\left[\mathrm{AlO}_{4}\right]$ tetrahedra.

3.2.4. Thermal Gravimetric Analysis. A comparison of the thermograms after $7 \mathrm{~d}$ of hydration of the slag solidified body without $\mathrm{SiC}$ whiskers and with $1 \% \mathrm{SiC}$ whiskers is shown in Figure 8. The initial temperature was $40^{\circ} \mathrm{C}$, rising to $800^{\circ} \mathrm{C}$ at a rate of $20^{\circ} \mathrm{C}$ per minute, and nitrogen was used as a protective gas for testing. Thermogravimetric curves can be used to know the composition, thermal stability, thermal decomposition, and the products produced by the sample and its possible intermediate products.

The decrease of sample weight below $100^{\circ} \mathrm{C}$ is mainly caused by free water evaporation. Combining the curves shows that the weight loss in the range of $100-300^{\circ} \mathrm{C}$ is mainly caused by the weak, free water dehydration in hydrated calcium silicate gel and calcium silica, where the mass losses of samples S2 and V were $7.76 \%$ and $7.55 \%$, respectively. There was little difference in mass loss between the two samples, indicating that the addition of $\mathrm{SiC}$ whisker did not affect the intermolecular force of hydration products greatly. The mass loss at $300^{\circ} \mathrm{C}$ to $700^{\circ} \mathrm{C}$ is caused by the cracking of some hydration products caused by the rupture of molecular bonds between calcium silicate hydrate gel and calcium silicate. Between $300^{\circ} \mathrm{C}$ and $700^{\circ} \mathrm{C}$, the mass losses of S2 and V were $10.63 \%$ and $10.26 \%$, respectively. There is no significant difference between the two samples, indicating that the addition of $\mathrm{SiC}$ whisker does not have much influence on the intramolecular force of slag hydration products. In conclusion, the addition of $\mathrm{SiC}$ whisker has no adverse effect on the thermal stability of slag hydration products.

3.3. The Mechanism Research. According to previous experiments in Sections 3.1.1 and 3.1.2, whisker can improve the compressive properties of slag. The mechanism of whisker will be explained in detail in this section.

From a microscopic point of view, the $\mathrm{SiC}$ whiskers improve the mechanical properties of the slag solidified body by effectively inhibiting the initiation and further development of early microcracks inside the slag body at the microscopic level. Its action mechanism is shown in Figure 9. When there is no whisker in the slag, the crack will develop without restriction, and then the compressive property of the slag will be reduced. When the whisker is contained in slag, the crack may stop directly at the whisker or spread slowly along the whisker. Both modes can reduce the crack propagation and thus improve the compressive properties of slag.

From a macro perspective, whiskers were dispersed uniformly in the slag solidified body contributing to the release of excess water, reducing the porosity. Whiskers also fill the gaps in the noncompact portion of the cement. In addition, many randomly distributed whiskers effectively overcome the phenomenon of stress concentration caused by the transformation of hydration products at the late stage of slag hydration. Its action mechanism is shown in Figure 10 . When there is no whisker in the slag, the stress tendency concentrates on the crack tip and promotes the crack to continue to grow. When there is whisker in the slag, 


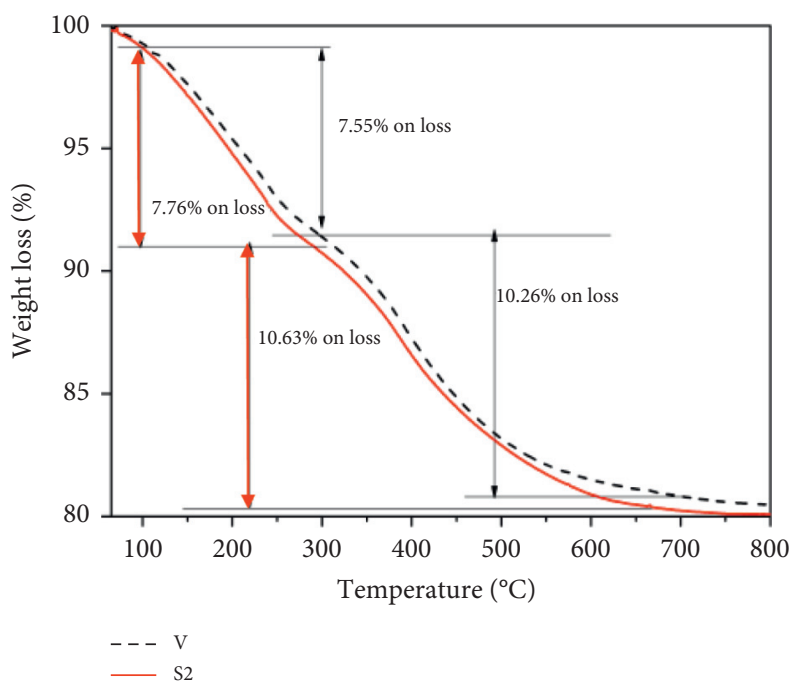

Figure 8: TG curves of slag solidified body without adding $\mathrm{SiC}$ whisker (V) and with $1 \% \mathrm{SiC}$ whisker (S2).

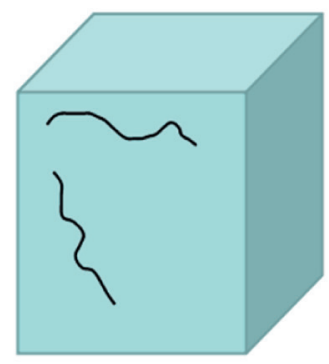

without whiskers

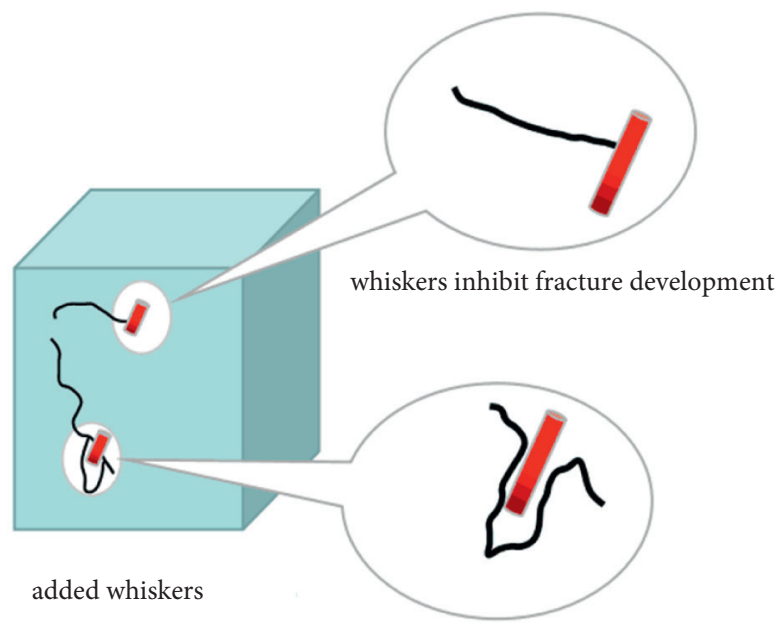

crack deflected along the whiskers

FIGURE 9: Crack propagation mechanism.

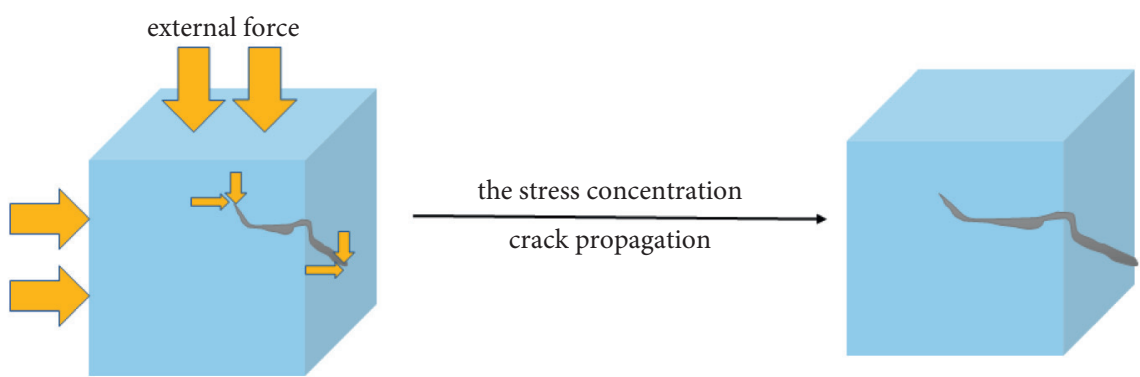

(a)

Figure 10: Continued. 


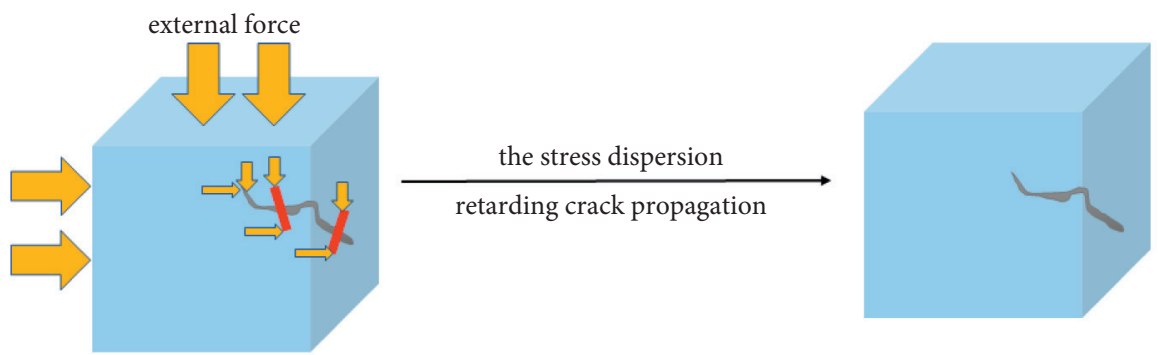

(b)

Figure 10: Stress distribution of slag (a) without whiskers and (b) with whiskers.

the whisker can disperse the stress concentration at the crack tip, restrain the crack propagation in the slag, and the compressive property of the slag is improved.

\section{Conclusions}

In this study, the mechanical properties and microstructure of slag solidified bodies with $\mathrm{SiC}$ whiskers at high temperatures were studied. The results showed that the compressive and tensile strengths of the slag were improved by $\mathrm{SiC}$ whiskers and that the microstructure was changed. The main findings are listed as follows:

(1) The addition of $1 \% \mathrm{SiC}$ whiskers resulted in the greatest improvement in the mechanical properties of the slag solidified body. After curing for $7 \mathrm{~d}$, the compressive strength and tensile strength were improved by $10.2 \%$ and $39.3 \%$, respectively. The triaxial test showed that the maximum stress of curing with $1 \% \mathrm{SiC}$ whiskers was $116 \%$ higher than that without $\mathrm{SiC}$ whiskers.

(2) SEM test shows that there are cracks in the microstructure of the slag, and the whiskers have the form of "pulled out" and "bridge." The "pulled out" state of the whiskers helps to disperse the stress on the slag, and the "bridge" state can connect the cracks of the slag. This improved the strength and toughness of the solidified body. Other analyses showed that $\mathrm{SiC}$ whiskers do not have a significant effect on the slag hydration product.

(3) The toughening mechanism of $\mathrm{SiC}$ whiskers was discussed and summarized. The addition of $\mathrm{SiC}$ whiskers suppressed the crack development of the solidified slag body and filled the gaps of the solid body. The random distribution of whiskers reduced stress concentration.

(4) The addition of $\mathrm{SiC}$ whisker improves the mechanical strength of slag and promotes the development of slag in oil well cement.

\section{Data Availability}

The data used to support the findings of this study are included within the article.

\section{Conflicts of Interest}

The authors declare that they have no conflicts of interest.

\section{Acknowledgments}

The authors would like to acknowledge the financial support provided by the CNPC Science and Technology Project (2020A-3913) and the National Natural Science Foundation of China (51874254). The authors are thankful for their financial support, and the authors also want to acknowledge the scientific assistance of The Center of Functional Materials for Working Fluids of Oil and Gas Field (SWPU, China).

\section{References}

[1] A. Thakkar, A. Raval, S. Chandra, M. Shah, and A. Sircar, "A comprehensive review of the application of nano-silica in oil well cementing," Petroleum, vol. 6, pp. 123-129, 2019.

[2] R. V. V. R. Murthy, M. Chavali, and F. Mohammad, "Synergistic effect of nano-silica slurries for cementing oil and gas wells," Petroleum Research, vol. 5, pp. 83-91, 2019.

[3] D. Jiapei, B. Yuhuan, C. Xuechao, S. Zhonghou, and S. Baojiang, "Utilization of alkali-activated slag based composite in deepwater oil well cementing," Construction and Building Materials, vol. 186, pp. 114-122, 2018.

[4] J. Yu and S. Dietmar, "The unusual solidification process of alkali activated slag and its relationshipwith the glass structure of the slag," Cement and Concrete Research, vol. 121, pp. 1-10, 2019.

[5] N. You, B. Li, R. Cao, J. Shi, C. Chen, and Y. Zhang, "The influence of steel slag and ferronickel slag on the properties of alkali-activated slag mortar," Construction and Building Materials, vol. 227, Article ID 116614, 2019.

[6] A. Laichaoui, A. Zidol, R. Mitiche-Kettab, A. Bali, and A. Tagnit-Hamou, "Effect of the type of superplasticizer on the properties of cementitious systems incorporating slag," Journal of Adhesion Science and Technology, vol. 33, no. 2, pp. 187-207, 2019.

[7] H. Wang, J.-J. Wu, X. Zhu, Q. Liao, and L. Zhao, "Energy-environment-economy evaluations of commercial scale systems for blast furnace slag treatment: dry slag granulation vs. water quenching," Applied Energy, vol. 171, pp. 314-324, 2016.

[8] B. Vafaei, K. Farzanian, and A. Ghahremaninezhad, "The influence of superabsorbent polymer on the properties of alkali-activated slag pastes," Construction and Building Materials, vol. 236, Article ID 117525, 2020. 
[9] J. Qiu, H. S. Tan, and E. Yang, "Coupled effects of crack width, slag content, and conditioning alkalinity on autogenous healing of engineered cementitious composites," Cement and Cencrete Composites, vol. 73, pp. 203-212, 2016.

[10] A. Hosan and F. U. Ahmed Shaikh, "RETRACTED: influence of nano-CaCO3 addition on the compressive strength and microstructure of high volume slag and high volume slag-fly ash blended pastes," Journal of Building Engineering, vol. 27, Article ID 100929, 2020.

[11] M. Li, Q. Mu, P. Yan, L. Liu, and X. Guo, "Brucite fibers on performance improvement and mechanism of high-temperature slag cementing slurries," Journal of Adhesion Science and Technology, vol. 34, no. 1, pp. 1-12, 2020.

[12] P. Wu, J. Wang, S. Hu, X. Cao, and X. Lyu, "Preparation and performance of slag-based binders for the cementation of fine tailings," Journal of Adhesion Science and Technology, vol. 32, no. 9, pp. 976-996, 2018.

[13] R. Manjunath, M. C. Narasimhan, M. Shashanka, S. D. Vijayanand, and J. Vinayaka, "Experimental studies on shear strength characteristics of alkali activated slag concrete mixes," Materials Today: Proceedings, vol. 27, pp. 275-279, 2019.

[14] M. Choolaei, A. M. Rashidi, M. Ardjmand, A. Yadegari, and H. Soltanian, "The effect of nanosilica on the physical properties of oil well cement," Materials Science and Engineering A, vol. 538, pp. 288-294, 2012.

[15] D. Velissariou, N. Katsiotis, P. Tsakiridis et al., "A combined study of the performance and hydration of a class $\mathrm{G}$ oil-well cement derived from Greek raw materials," Construction and Building Materials, vol. 197, pp. 63-71, 2019.

[16] D. Chen, J. Guo, Y. Xu et al., "Adsorption behavior and mechanism of a copolymer used as fluid loss additive in oil well cement," Construction and Building Materials, vol. 198, pp. 650-661, 2019.

[17] A. Buchman, H. Dodiuk-Kenig, A. Dotan, R. Tenne, and S. Kenig, "Toughening of epoxy adhesives by nanoparticles," Journal of Adhesion Science and Technology, vol. 23, no. 5, pp. 753-768, 2009.

[18] M. Li, S. Deng, Y. Yu, J. Jin, Y. Yang, and X. Guo, "Mechanical properties and microstructure of oil well cement stone enhanced with Tetra-needle like $\mathrm{ZnO}$ whiskers," Construction and Building Materials, vol. 135, pp. 59-67, 2017.

[19] M. Li, Y. Yang, M. Liu, X. Guo, and S. Zhou, "Hybrid effect of calcium carbonate whisker and carbon fiber on the mechanical properties and microstructure of oil well cement," Construction and Building Materials, vol. 93, pp. 995-1002, 2015.

[20] M. Li, M. Liu, Y. Yang, Z. Li, and X. Guo, "Mechanical properties of oil well cement stone reinforced with hybrid fiber of calcium carbonate whisker and carbon fiber," $\mathrm{Pe}$ troleum Exploration and Development, vol. 42, no. 1, pp. 104-111, 2015.

[21] R. A. Hanna, P. J. Barrie, C. R. Cheeseman, and C. Hills, "Solid state ${ }^{29} \mathrm{Si}$ and ${ }^{27} \mathrm{Al}$ NMR and FTIR study of cement pastes containing industrial wastes and organics," Cement and Concrete Research, vol. 25, no. 7, pp. 1435-1444, 1995.

[22] A. A. Melo Neto, M. A. Cincotto, and W. Repette, "Drying and autogenous shrinkage of pastes and mortars with activated slag cement," Cement and Concrete Research, vol. 38, no. 4, pp. 565-574, 2008. 